\title{
iPark: automated smart parking system
}

\author{
Rahman Atiqur \\ Information and Communication Engineering, Chongqing University of Posts and Telecommunications, P. R. China
}

\begin{tabular}{l} 
Article Info \\
\hline Article history: \\
Received Jun 27, 2020 \\
Revised Feb 4, 2021 \\
Accepted Mar 11, 2021 \\
\hline Keywords: \\
Communication technologies \\
Image processing \\
Internet of things (IoT) \\
Raspberry Pi4 \\
Sensing unit \\
Smart city
\end{tabular}

Article Info

Article history:

Received Jun 27, 2020

Revised Feb 4, 2021

\author{
Communication technologies \\ Image processing \\ Internet of things (IoT) \\ Sensing unit \\ Smart city
}

\begin{abstract}
Parking problems became ubiquitous and are growing at an alarming rate in every major city. It causes parking problems which cause traffic jams, driver frustration, and pollution. Time we visit different public places for example shopping centers, multiplex movies hall and lodging houses during carnivals or holidays, it makes the added parking difficult. Checking out a parking lot results in $40 \%$ to $50 \%$ of traffic jams. Due to this, car parking, in turn, causes the traffic issue. There are some problems associated with car parking like the way to control the amount of cars within the parking zone, monitoring the movement of the car in/outside of the parking zone, checking whether there's an area inside for more cars or not, and therefore the safety to park. This paper proposes an answer to these problems using the concept of the web of Things. iPark is a fully automated system that senses the entry and exit of a car, displays the entire number of cars parked within the parking zone on screen, and the way many free spaces are available within the parking lot.
\end{abstract}

This is an open access article under the CC BY-SA license.

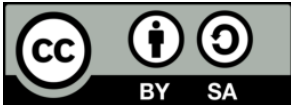

\section{Corresponding Author:}

Rahman Atiqur

School of Information and Communication Engineering

Chongqing University of Posts and Telecommunications

Chongqing, 400065, P.R. China

Email: bulbul.cse.cu@gmail.com

\section{INTRODUCTION}

Usually, a lot of difficulties attain during a manual car parking scheme similar to control, time consumption, and gasoline wastage. The prevailing parking system doesn't provide an efficient thanks to predicting and spot vehicle occupancy in real-time. Whenever we've to park a car within the parking structure, we've to manually look for a parking slot. These tricky increases when the parking organization is full or multi-storied. This originates traffic controlling difficulties and avoidable time feeding in blast epochs. Hence, the prevailing system doesn't enable better real-time monitoring and management of obtainable spaces within the parking lot. All this causes inconvenience for the people. We face various problems associated with car parking like the way to control the amount of the car within the parking zone, monitoring the movement of the car in/outside of the parking zone, check whether there's an area inside for more cars or not and therefore the safety to park. I've implemented a sensible system by using various technologies and advanced research [1]. The smart parking system is implemented in many environments with various features, which solves the issues faced within the day-to-day activities.

The most idea behind the smart car parking system is to assist the user to seek out areas where parking is out there and therefore the number of slots free therein area. My recommended system reduces the time taken to see space for the vehicle. It also helps in reducing fuel consumption. My recommended system uses ultrasonic sensors to sense the car [2].

There are three tired functionalities, rock bottom level comprising the sensing functionality, a middle tier handling data forwarding, and therefore the upper-tier handling data storage, processing, and client interfaces [3]. My recommended system uses image processing using the ANPR technique to detect the 
license plate of the car. I've also added the functionality to calculate the wages automatically [4]-[6]. The utilization of iOS technology combined with the recent advances in wireless applications is that the key to unraveling emerging parking problems [7].

In section 2 we talk about the literature review. Section 3 presents the smart car parking system's implementation details and describes how the system works. Section 4 are about the idea of dataset. Section 5 gives an overview of all resultset found in my systems and section 6 concludes the paper.

\section{LITURATURE REVIEW}

The succeeding is some papers that were referenced for the development.

a. "Automatic Multilevel Car Parking System" in Int. J. of Electrical and Microelectronics Research, ISSN 2348-6988 Vol. 3, No. 2, pp: (438-441), Mon.: April-June 2015 by Gupta A., Jaiswar A., Agarwal Ha., Shankar Ch. [1]. In this article, the authors have presented and labeled the idea of an "automatic car parking system", which can inevitably sense the entrance and leaving of the cars, number of cars shown on the LCD. This automated car parking system decreases the time consumed to check the space for the cars. At this point, the authors have advised the use of sensors to sense the existence of the car.

b. "Smart Parking System with Image Processing Capability",

I.J. Intelligent Systems, App., 2012,3, 41-47 available online Ap 2012 in MECS by Reza, M.F. Ismail, A. A. Rokoni, M.A.R Sarkar [2], [5], [6], [7]. This article has presented the smart parking systems which take the info about vacant parking spaces, process it, and then place the car at an assured spot. As well, the authors have announced an idea of an ophthalmic character recognition technique, i.e., "ANPR" for license plate recognition of vehicles.

c. "Android-based Smart Parking System" in Int. J. of Innovative Research in Computer Engg Vol. 3, May 2015 by Pallavi M., Radha De., Samiksha Na., Shubhangi M., Shraddha Sa. [3]. in this article, the authors have offered a plan for an "Android-based smart Parking System" that controls the sum of cars to be parked in the selected parking zone. This is completed by computerizing the parking and unloading of the vehicle with the aid of an Android Application. An Android application will aid the operator to catch out the precise parking slot assigned to him in the parking zone. Information will be read locally. Commands to the assigned parking slot will be displayed to the operator [3].

d. "ASPS using internet of things (IoT)" in Int. Journal of Scientific and Research Publications, Vol. 5, No. 12, Dec 2015629 ISSN 2250-3153 by Mr. Basavaraju S. R [4]. In this publication, the author has presented an idea of the internet of things (IoT) which shows a vigorous role in attaching the adjacent environmental kits to the setup. The Author has recommended the use of groupings of IoT like detecting, processing as well as connectivity of data. Similarly, the author presented a plan for a smart parking system by creating the use of IoT viable h/w such as Arduino UNO microcontroller which consumes less power.

\section{IMPLEMENTATION DETAILS}

\subsection{System outline}

The system structural design displays the diagram of the smart parking system. At the entrance point, when the car arrives at the parking lot, web camera takes the image of license plates, and the image processing entity is used to transform it into text layout, and it is used to assign a parking slot which is then kept into databank. When the vehicle is parked in the assigned parking slot, then sensing unit perceives the existence of a vehicle in the parking slot [4]. The Raspberry Pi unit then processes this raw data and hold it into a database through the internet via Ethernet Port. Figure 1 graphycally shows all the things [4].

The iOS application offers the precise route of the assigned parking slot to the operator. The application then proceeds the assigned parking slot number as an input and shows the route that the operator needs to track to touch the parking slot. The data is retrieved locally. Figure 2 graphically shows how the iOS application works [3]. 


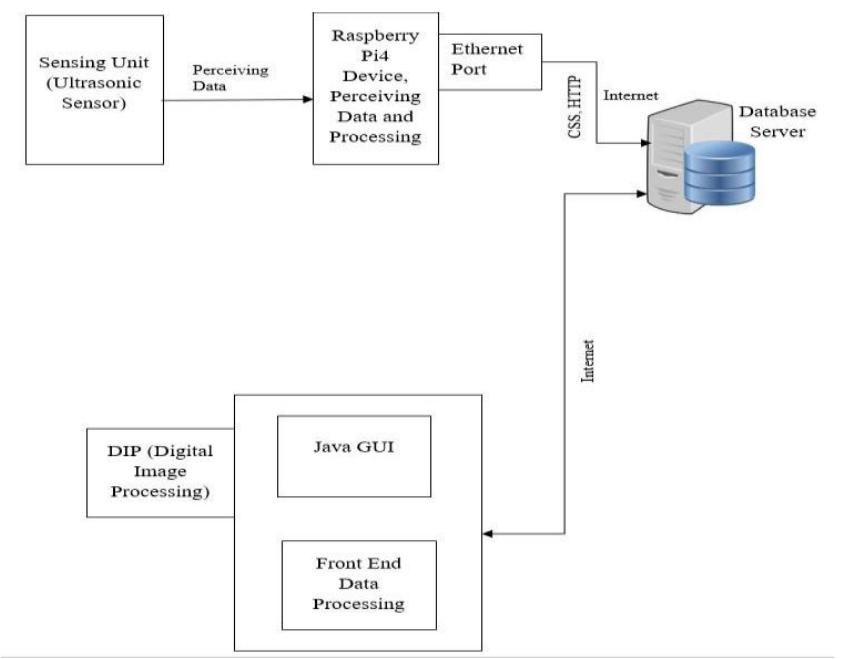

Figure 1. System model of recommended smart car parking system

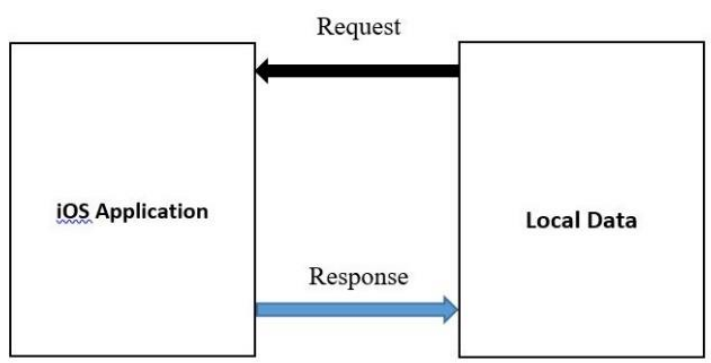

Figure 2. iOS application

\subsection{Sections}

The recommended system is alienated into following five sections:

\section{a. Perceiving parts}

The ultrasonic sensors are cast-off to sense the existence of the vehicle. Ultrasonic sensors are vicinity sensors. These sensors sense the existence of the somatic object without coming in communication with that object, so the lifecycle of these sensors is greater [8]. In this recommended system, we use HCSR04 ultrasonic distance calculating sensor which is competent to sense an object at distance covered from $1.5 \mathrm{~cm}$ to $50.5 \mathrm{~cm}$. Ultrasonic sensor entails transmitter, receiver, and regulator unit with a trigger, echo, and $\mathrm{I} / \mathrm{O}$ pinches. The data restrained by the sensors is composed [9].

\section{b. Raspberry Pi device}

It is the general-purpose computer unit, which processes the data composed by sensors and brings up to date the database. The resultant modifications are redirected in the database and shown on the front termination [10]. The Raspberry Pi unit processes the data directed from the sensors then sends it to the database with Ethernet ports using the internet. The data directed by the sensors are analog data. The Raspberry Pi unit transforms that raw analog data into a digital layout [11]. The digital data is cast-off and a default variety for car parking is agreed upon. A predefined range is associated with the range restrained by the sensors. Depending on this standing of a parking lot is determined.

\section{c. Ethernet ports}

For linking the Raspberry Pi unit to the database, Raspberry Pi's ethernet port is used. The Raspberry ethernet port connects the Raspberry Pi unit to the internet in a few minutes. An ethernet port is attached to the Raspberry Pi board which assists connectivity to the internet over the ethernet [12]. The ethernet port doings as a gateway for the arrangement which is useful to contact online repositories. I have 
used standard ethernet libraries delivered by the Raspberry Pi unit to read and write the information. The Raspberry Pi unit is associated with the database via the internet [13].

\section{d. Image processing}

I have used a method known as "RFID reader" in my recommended scheme. The RFID reader is a device that usages optical character recognition on images to read car registration plates [14]. With the help of an inbuilt RFID camera, the system will capture a picture of the number plate of the car, and I have designed a code that transforms it into text format which is further kept in the database inevitably [15]-[17]. The javaanpr.jar file is cast-off for image processing. This file comprises numerous inbuilt libraries that are used for matching and processing the image [18]-[21]. The RFID Image retraction technique comprises of following steps:

- Number plate region detection,

- Plate fragmentation,

- Feature mining and standardization of characters,

- Recognition of characters.

\section{e. iOS application}

An iOS application is developed using Eclipse. The iOS application aids the operator to find out the precise parking slot assigned to him/her in the parking zone. Data is retrieved locally. Instructions to the assigned parking slot are displayed to the operator [22].

\subsection{Algorithm}

There are seven basic algorithms that the software needs for recognizing a license plate:

- Plate localization-This method is liable for finding and separating the plate on the image.

- Plate positioning and sizing-This method pays for the skew of the plate and amends the dimensions to the obligatory dimension.

- Normalization-This method modifies the brightness, contrast of the picture.

- Character segmentation-This method is cast-off to find individual characters on the plates of the vehicle.

- Optical character recognition.

- Syntactical/Geometrical analysis-This method is cast-off check characters and positions against countryspecific instructions.

- The averaging of the recognized value over several fields/images is completed to yield a more dependable and assured outcome. Particularly in the case of any solo image may cover an echoed light flash, be partly buried, or other short-term outcomes.

\subsection{Experimental setup}

The succeedings are the hardware and software requests for the recommended scheme:

a. Hardware requests

- Raspberry Pi 4 board

- HC-SR04 Ultrasonic Parking Sensors

- REES52 Finest USB AB Cable

- RFID reader Camera

b. Software requirements

- Arduino IDE installed Raspberry Pi4 device

- JDK- Eclipse

- Databank- MySQL

\section{DATASET}

The values from the ultrasonic parking sensors are a chunk of the dataset. The concentrated range of the sensors is $50.5 \mathrm{~cm}$. The blind mess for the sensors is $1.5 \mathrm{~cm}$. The databank has passed for the time at which the vehicle was parked, the parking slot no. and standing [23]. The standing of a parking slot can be empty (0), booked (1), parked (2), the input for the RFID camera is an image of the number plate. 


\section{RESULTS AND DISCUSSION}

The next are the snapshots for the automated smart parking system as shown in Figure 3.

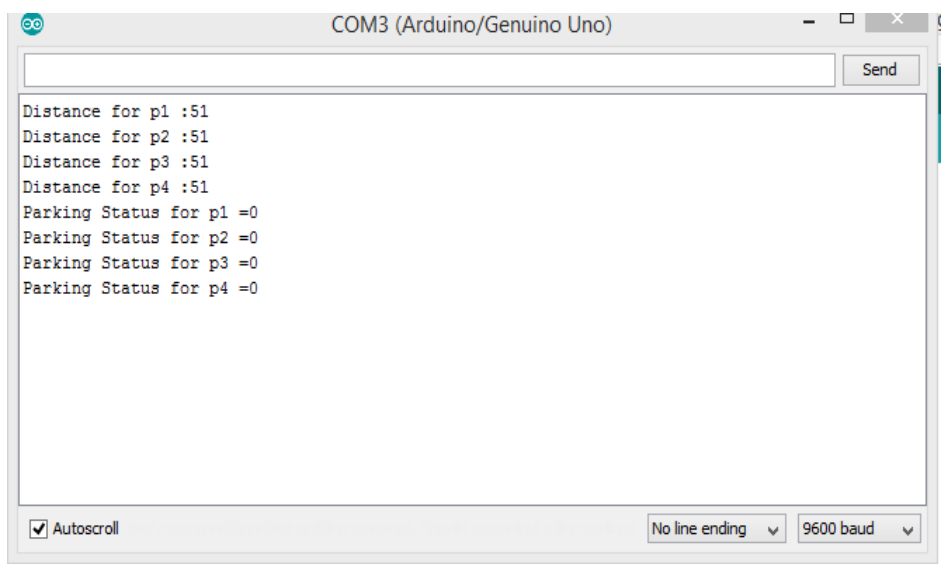

Figure 3. Raspberry Pi integrated arduino monitor display

The beyond screenshot displays serialized monitor display used in Arduino integrated raspberry pi4 tool. When a vehicle is parked in the assigned parking slot, the serialized monitor displays the supreme distance of the vehicle from ultrasonic parking sensors. The screenshot displays supreme distance that ultrasonic parking sensors can sense is $51 \mathrm{~cm}$ for parking slot p1, p2, p3, and p4. Figure 4, this screenshot demonstrates parking status for parking slot P1, P2, P3, and P4 depending upon whether a vehicle is parked or not.

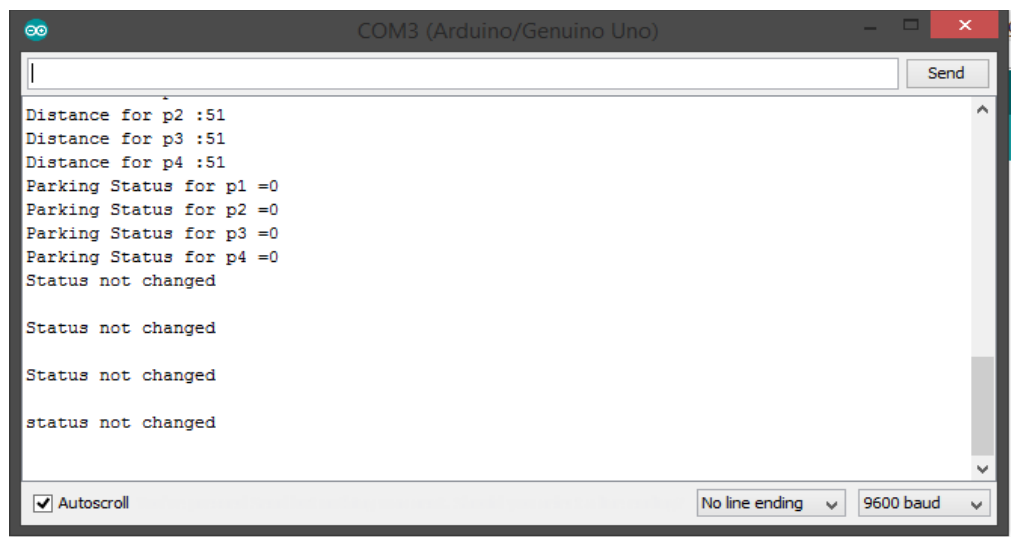

Figure 4. Displays the parking status

Figure 5, this screenshot displays distance of cars from sensors at what time vehicle is parked in parking slot number $\mathrm{P} 3$ and $\mathrm{P} 4$. Therefore, it displays parking status=1 for parking slot P3 and P4. Meanwhile, no vehicles are parked in slot P1 and P2, their status ruins unaffected [24]. 


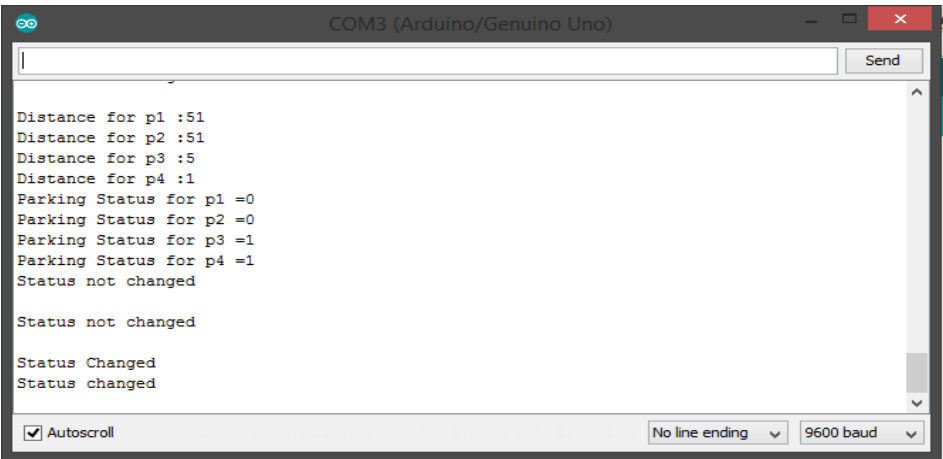

Figure 5. Parking status

Figure 6 displays the admin login screen from where the admin can access the whole system using iOS apps. The below screenshot displays an unoccupied parking lot in the iOS application. From the figure, we see that parking lots $\mathrm{P}, \mathrm{P} 2, \mathrm{P} 3$, and $\mathrm{P} 4$ are vacant for the first time. When a lot is reserved then the occupied lot screenshot is displayed in the Figure 7 [25].

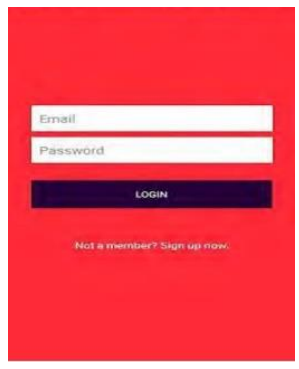

Figure 6. Admin login page

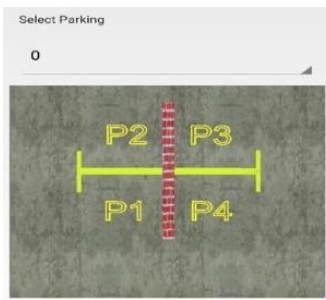

Figure 7. Displays the empty parking slot

Figure 8 this screenshot displays the parking directions for parking slot 1 . From this figure, we observed that when an operator selects a lot P1 then it is occupied.

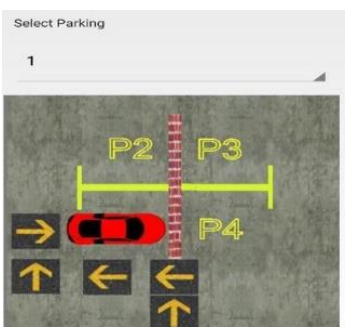

Figure 8. Screenshot of occupied parking slot 


\section{CONCLUSION}

Today, the tricky of parking is remarkable as there is no appropriate idea in place. The present vehicle parking system is inadequate. To settle this tricky, I have implemented a smart parking system (iPark) which allows the parking of cars and thus lessens the time in use to check the space to be cast-off by showing the spot where the space for parking is vacant. In this article, a competent car parking system is recommended which rigorously diminishes the parking difficulties. This article displays how the parking tricky in crowded spaces can be controlled with a well-thought strategy. It aids the users to catch out the accessibility of a parking slot in the parking zone, get the accessibility setting, and touch to the assigned parking slot within the parking zone. It aids to marks the supervision tranquil on the manager side. It also saves the time of the users necessary for examining a parking slot. Thus, the planned smart parking system is simple, cost-effective, and more effective as compared to present systems and offers enhanced client service.

\section{ACKNOWLEDGEMENTS}

All praise and thanks are to ALLAH Almighty. After that, I would like to express my profound appreciation concerning my supervisor, Professor Dr. Yun Li for his endless supervision, promising assistance as well as motivating disputes. I am obliged to the School of Information and Communications Engineering for their livelihood.

\section{REFERENCES}

[1] Ankit G, Ankit J, H. Agarwal, Chandra S, “Automatic Multilevel Car Parking” in International Journal of Electrical and Electronics Research, ISSN2348-6988, vol.3, issue2, pp: (438- 441), Month: April-June2015.

[2] M. O. Reza, M. F. Ismail, A. A Rokoni, M. A. R Sarkar, "Smart Parking System with Image Processing Facility" in International Journal Intelligent Systems and Applications, vol. 3, pp. 41-47, 2012. [Online]. Available: https://www.researchgate.net/profile/M-

Sarkar/publication/224910014_Smart_Parking_System_with_Image_Processing_Facility/links/00b7d53c8f20b206 22000000/Smart-Parking-System-with-Image-Processing-Facility.pdf.

[3] Pallavi M, Radha De, Samiksha Na, Shubhangi Mu, Shraddha Sa, "Android based Smart Parking System," in International Journal of Innovative Research in Computer and Communication Engineering, vol. 3, no. 5, pp. 3981-3985, May 2015. [Online]. Available: https://www.researchgate.net/publication/279280033_Android_based_Smart_Parking_System.

[4] Mr. Basavaraju S. R, "Automatic Smart parking System using Internet of Things (IoT)," in International Journal of Scientific and Research Publications, vol. 5, no. 12, pp. 629-632, 2015. [Online]. Available: http://citeseerx.ist.psu.edu/viewdoc/download?doi=10.1.1.735.8030\&rep=rep1\&type=pdf\#page=638.

[5] Serkan Ozbay, Ergun Ercelebi, "Automatic Vehicle Identification by Plate Recognition," in World Academy of Science and Technology, vol. 9, pp. 222-225, 2007. [Online]. Available: https://static.scaytrase.ru/cnr/article-cnreng.pdf.

[6] Priyamvadha Krishnakumar, "Automatic Number Plate Recognition (ANPR) through smart Phones using Image Processing Techniques," in IOSR Journal of VLSI and Signal Processing (IOSR-JVSP), vol. 4, no. 4, pp. 19-23, 2014. [Online]. Available: https://www.researchgate.net/publication/284364806_Automatic_Number_Plate_Recognition_ANPR_through_sm art_Phones_using_Image_Processing_Techniques.

[7] Teena Singh R, "Automatic Vehicle Number Plate Recognition Using Morphological Edge Detection and Segmentation" in International Journal of Emerging Technology and Advanced Engineering, vol. 5, no. 1, pp. 501504, 2015. [Online]. Available: https://1library.net/document/z3137o8y-automatic-vehicle-number-platerecognition-morphological-detection-segmentation.html.

[8] A. Khanna, R. Anand, "IoT based smart parking system," 2016 International Conference on Internet of Things and Applications (IOTA), Pune, India, 2016, pp. 266-270.

[9] W. Alsafery, B. Alturki, S. Reiff-Marganiec, K. Jambi, "Smart Car Parking System Solution for the Internet of Things in Smart Cities," 2018 1st International Conference on Computer Applications \& Information Security (ICCAIS), Riyadh, Saudi Arabia, 2018, pp. 1-5.

[10] M. Fraifer, M. Fernström, "Smart car parking system prototype utilizing CCTV nodes: A proof of concept prototype of a novel approach towards IoT-concept based smart parking," 2016 IEEE 3rd World Forum on Internet of Things (WF-IoT), Reston, VA, USA, 2016, pp. 649-654.

[11] Shruthi Mudaliar, Shreya Agali, Sujay Mudhol, Chaitanya K Jambotkar, "IoT based smart car parking system," International Journal of Advanced Research in Science, Engineering and Technology, vol. 5, no. 1, pp. 270-271, 2019. [Online]. Available: https://www.researchgate.net/profile/Chaitanya-Jambotkar2/publication/332574743_IoT_Based_Smart_Car_Parking_System/links/5cbefc7192851c8d22fecf3b/IoT-BasedSmart-Car-Parking-System.pdf.

[12] Natarajan P. B, Samit Kumar Ghosh, "Design and implementation of smart car parking system using lab view," International Journal of Pure and Applied Mathematics, vol. 120, no. 6, pp. 329-338, 2018. [Online]. Available: https://acadpubl.eu/hub/2018-120-6/9/835.pdf. 
[13] Bachhav, Jayakshei Dadaji, M. A. Mechkul, "Smart car parking system," International Research Journal of Engineering and Technology, vol. 4, no. 6, pp.3036-3038, 2017. [Online]. Available: https://www.irjet.net/archives/V4/i6/IRJET-V4I6741.pdf.

[14] Nandyal Suvarna, Sabiya Sultana, Sadaf Anjum, "Smart car parking system using arduino uno," International Journal of Computer Applications, vol. 169, no. 1, pp. 0975-8887, 2017. [Online]. Available: https://www.ijcaonline.org/archives/volume169/number1/nandyal-2017-ijca-914425.pdf.

[15] B. M. Mahendra, S. Sonoli, N. Bhat, Raju, T. Raghu, "IoT based sensor enabled smart car parking for advanced driver assistance system," 2017 2nd IEEE International Conference on Recent Trends in Electronics, Information \& Communication Technology (RTEICT), Bangalore, India, 2017, pp. 2188-2193.

[16] P. Sadhukhan, "An IoT-based E-parking system for smart cities," 2017 International Conference on Advances in Computing, Communications and Informatics (ICACCI), Udupi, India, 2017, pp. 1062-1066.

[17] Gandhi B. K, Rao M. K, "A prototype for IoT based car parking management system for smart cities," Indian Journal of Science and Technology, vol. 9, no. 17, pp. 1-6, 2016. [Online]. Available: https://sciresol.s3.us-east2.amazonaws.com/IJST/Articles/2016/Issue-17/Article43.pdf.

[18] D. Vakula, Y. K. Kolli, "Low-cost smart parking system for smart cities," 2017 International Conference on Intelligent Sustainable Systems (ICISS), Palladam, India, 2017, pp. 280-284.

[19] Atiqur Rahman, Yun Li, "Automated smart car parking system using raspberry Pi 4 and iOS application," International Journal of Reconfigurable and Embedded Systems, vol. 9, no. 3, pp. 229-234, 2020. http://ijres.iaescore.com/index.php/IJRES/article/view/20295.

[20] Yanxu Zheng, S. Rajasegarar, C. Leckie, "Parking availability prediction for sensor-enabled car parks in smart cities," 2015 IEEE Tenth International Conference on Intelligent Sensors, Sensor Networks and Information Processing (ISSNIP), Singapore, 2015, pp. 1-6.

[21] A. Khanna, R. Anand, "IoT based smart parking system," 2016 International Conference on Internet of Things and Applications (IOTA), Pune, India, 2016, pp. 266-270.

[22] A. Roy, J. Siddiquee, A. Datta, P. Poddar, G. Ganguly, A. Bhattacharjee, "Smart traffic \& parking management using IoT," 2016 IEEE 7th Annual Information Technology, Electronics and Mobile Communication Conference (IEMCON), Vancouver, BC, Canada, 2016, pp. 1-3.

[23] T. N. Pham, M. Tsai, D. B. Nguyen, C. Dow, D. Deng, "A Cloud-Based Smart-Parking System Based on Internetof-Things Technologies," in IEEE Access, vol. 3, pp. 1581-1591, 2015.

[24] M. B. Ahmad, A. A. Abdullahi, A. S. Muhammad, Y. B. Saleh, U. B. Usman, "The Various Types of sensors used in the Security Alarm system," International Journal of New Computer Architectures and their Applications, vol. 9, no. 2, 50, $2019 . \quad$ [Online]. Available: https://www.researchgate.net/publication/340479748_The_Various_Types_of_sensors_used_in_the_Security_Alar m_system.

[25] M. B. Ahmad, M. Cavas, "A review advancement of security alarm system using internet of things (IoT)," International Journal of New Computer Architectures and their Applications, vol. 9, no. 2, pp.38-49, 2019. [Online].Available:

https://www.researchgate.net/publication/337544365_A_REVIEW_ADVANCEMENT_OF_SECURITY_ALARM _SYSTEM_USING_INTERNET_OF_THINGS_IoT.

\section{BIOGRAPHY OF AUTHOR}

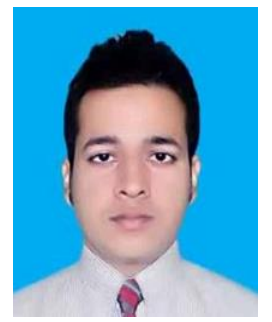

Mr. Rahman Atiqur received his Bachelor of Science (B.Sc) and Master of Engineering (M.Engg.) degree from the Department of Computer Science and Engineering at the University of Chittagong, Chittagong, Bangladesh. In profession, he worked in the Department of Computer Science and Engineering, University of Chittagong, Bangladesh as an Assistant Professor since April 2016. Former he was a lecturer in the Department of Computer Science and Engineering, University of Chittagong, Bangladesh. He is now conducting his Ph.D. research works under the Chinese Government Scholarships (CGS) Program at Chongqing University of Posts and Telecommunications, Chongqing, China. His current research interest lies in the field of edge computing-based IoT systems. 